\title{
Chlorinated biphenyl degradation by wild yeasts pre-cultured in biphasic systems
}

\author{
M. Cristina Romero* \\ Micología Médica e Industrial, Microbiología \\ Facultad de Ciencias Veterinarias \\ Universidad Nacional de La Plata \\ Av. 60 e/ 119 y 120 s/nro., 1900 \\ La Plata, Argentina \\ Tel: 00542214250577 \\ Fax: 00542214222904 \\ E-mail: cmriar@yahoo.com.ar

\section{Enso Hugo Reinoso} \\ Micología Médica e Industrial, Microbiología \\ Facultad de Ciencias Veterinarias \\ Universidad Nacional de La Plata \\ Av. 60 e/ 119 y 120 s/nro., 1900 \\ La Plata, Argentina \\ Tel: 00542214247642 \\ E-mail: reinoso@fcv.unlp.edu.ar
}

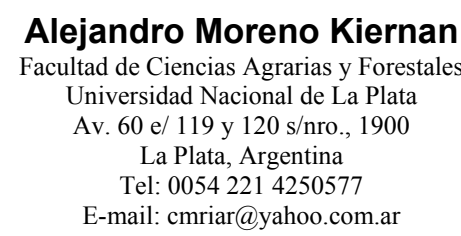

\section{Inés Urrutia}

Facultad de Ciencias Agrarias y Forestales

Universidad Nacional de La Plata

Av. 60 e/ 119 y 120 s/nro., 1900

La Plata, Argentina

Tel: 00542214835934

E-mail: urrutia@isis.unlp.edu.ar

Financial support: This work was supported by grants from the National Council of Scientific and Technological Research (CONICET) and from the National University of La Plata (UNLP- Facultad de Ciencias Veterinarias), Argentina.

Keywords: biphasic system, fungal adaptation, increased solubilities, transformation rates, yeasts communities.

Abbreviations: $\mu$ : specific growth rate
$\mu_{\max }:$ maximum specific growth rate
DCB: 2,4-dichlorobiphenyl
GC: gas chromatography
$\mathrm{K}_{\mathrm{i}}$ : inhibition constant
$\mathrm{K}_{\mathrm{s}}$ : saturation constant
MSM: mineral salts medium
OD: optical density
PCBs: polychlorinated biphenyls
S: substrate level
TCB-3': 2,3',4- trichlorobiphenyl
TCB-4': 2,4',5-trichlorobiphenyl

Environmental biotechnology has developed as an offshoot from sanitary engineering, and only recently the biological component of the ecosystems had been recognized as relevant when bioremediation strategies must be chosen to solve environmental problems. Yeasts were isolated on 2,4-dichlorobiphenyl, 2,3',4- and 2,4',5trichlorobiphenyl, poorly soluble compounds in water, as carbon sources. Debaryomyces castelli, Debaryomyces maramus and Dipodascus aggregatus composed the mixed culture and represented $72 \%$ of the isolates; their

*Corresponding author 
degradation potential were studied in biphasic and monophasic systems. The biphasic cultures were obtained with phenol as the organic phase and MSM as the aqueous ones, the monophasic medium only with MSM. Both cultures were supplied with 50, 100, 150 and 200 ppm DCB, TCB-3' and TCB-4' as substrate. The growth rates varied with the dispersion degree, agitation rates and cell adhesion to the organic phase. The water-phenolic system improved yeasts selection in pollutant presence with low water solubilities, indeed, the adaptation and degradation were more slowly in the monophasic aqueous medium. Bioremediation is based on the presence of efficient microbial populations and pollutant availability; the tested yeasts and the organicwater system assayed put forward the possibility that hydrophobic substrates could be mineralized in natural habitats by wild yeast consortium.

Successful detoxification of polluted areas is the result of interrelated factors, such as the contaminant toxicity, organism's degradation potential and ecological conditions. The first and major problem in environmental biotechnology is the microbial selection, as the organisms must transform significant amount of toxicants in a short conversion times and produce no-toxic metabolites. Up to date, the research on fungal degradation of pollutants has focused mostly on basidio- and zygomycetes species, but in heavy polluted sites, increasing yeast standing stock had been observed (Oudin et al. 1999; Sietmann et al. 2001; Romero et al. 2004).

This situation leads to consider wild yeasts as a promising organism to clean-up chemicals, and to assess them to develop environmental biotechnologies. Few researches had pointed out these advantages (Sietmann et al. 2002; Romero et al. 2002; Romero et al. 2005).

Polychlorinated biphenyls (PCBs) had been widely used as plasticizers, flame retardants, heat transfer, hydraulic and dielectric fluids, due to their physical-chemical inertness, but they are mutagenic and strongly toxic, so listed as priority pollutants by the US Environmental Protection Agency (USEPA, 2003). Bioremediation is an effective strategy to detoxify many contaminants, and efforts to engineer degradation-systems for PCBs polluted areas had been studied (Abramowicz, 1990; Swannell et al. 1996; Stringer and Johnston, 2001).

When a low-soluble toxicant, like PCBs congeners, is mixed with an aqueous medium given a byphasic system, the cells in the water-phase are in contact with less xenobiotic concentration than the yeasts adhered to the organic drops, therefore with high pollutant bioavailability (Hammer et al. 1998). Moreover, fungal adaptation is preceded by an acclimation time, requiring the low-soluble substrates longer periods, in these cases the organic presence improve the transformation rates (Havel and Reineke, 1995; Löser et al. 1999). So, the aims of this study were to evaluate the biodegradation of DCB, TCB-3' and TCB-4' by a natural yeast community; to compare their uptake in mono and biphasic cultures, and to assess the removal of poor water-soluble PCBs.

\section{MATERIALS AND METHODS}

\section{Yeasts isolation and identification}

Surface sediments were taken from natural and artificial channels that drain to Rio de La Plata (Argentina), then decimal diluted samples were assayed for the presence of PCBs-degrading yeasts by standard spread-plate methods, by triplicate. The species were purified by streaking repeatedly on mineral salts medium-agar (MSM, Romero et al. 2002) with 50 ppm DCB, or TCB-3' or TCB-4' as carbon sources. The plates were incubated at $27 \pm 1^{\circ} \mathrm{C}$, at $120 \mathrm{rpm}$, during 45 days; sterile controls were simultaneously incubated. The same PCBs-medium was employed to enumerate the total degrading species, by spread-plate methods, by triplicate, to obtain the studied yeasts percentage.

The yeast community was selected by enriched cultures performed in biphasic, water-phenol, and aqueous monophasic systems, amended with 50 ppm DCB, TCB-3' or TCB-4'. Cultures aliquots were spread on MSM-plates with the xenobiotics and the colony types were isolated. Yeast species were identified using morphological and biochemical tests, additional determinations and growth characteristics were also done (Kurtzman and Fell, 1998).

Table 1. Specific growth rates $\left(\mu, h^{-1}\right)$ in biphasic systems and $150 \mathrm{ppm}$ of each PCBs.

\begin{tabular}{|l|c|c|c|}
\hline & DCB & TCB-3' & TCB-4' \\
\hline D. castelli & $0.40 \pm 0.01$ & $0.30 \pm 0.03$ & $0.40 \pm 0.01$ \\
\hline D. maramus & $0.35 \pm 0.01$ & $0.46 \pm 0.02$ & $0.40 \pm 0.01$ \\
\hline D. aggregatus & $0.40 \pm 0.01$ & $0.45 \pm 0.02$ & $0.42 \pm 0.01$ \\
\hline mixed culture & $0.75 \pm 0.02$ & $0.80 \pm 0.01$ & $0.83 \pm 0.02$ \\
\hline
\end{tabular}


a

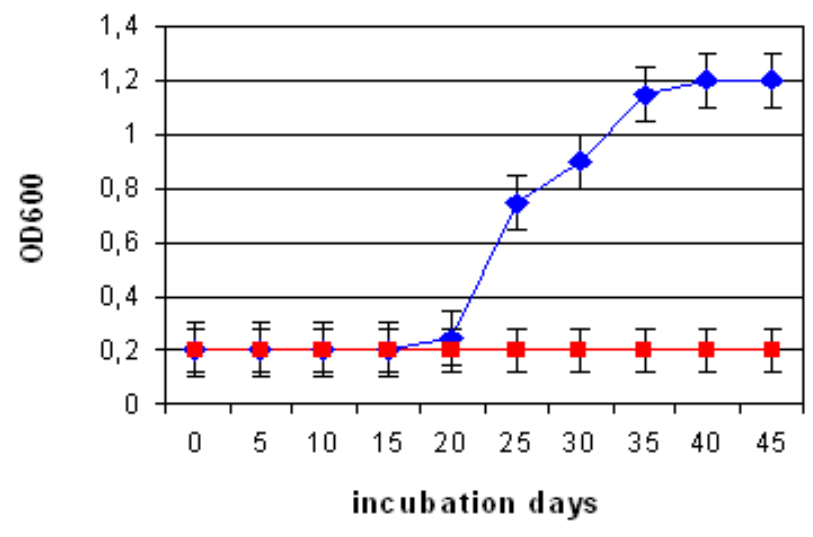

$\longrightarrow$ OD600 $\rightarrow$ control culture

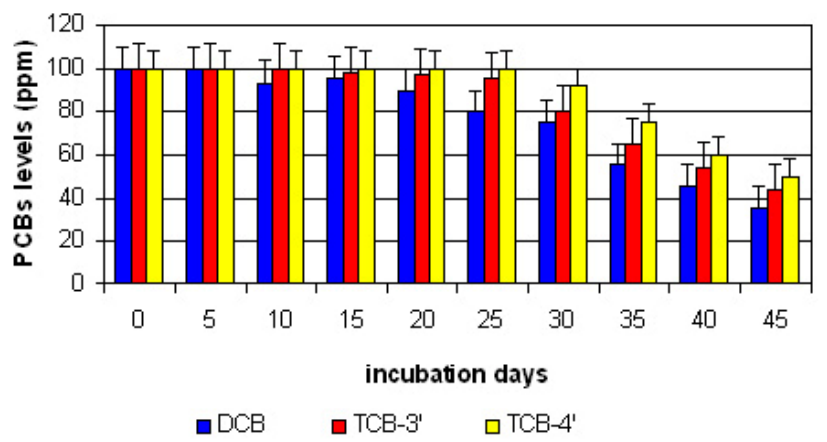

Figure 1. Growth curves (a) and PCBs concentrations (b) in biphasic system of non-acclimated consortium.

\section{Bioassays}

The biphasic system was obtained with phenol as the organic phase and MSM as the aqueous ones, the monophasic medium consisted only of MSM. Both systems were supplied with 50, 100, 150 and 200 ppm 2,4dichlorobiphenyl; or 2,3',4- or 2,4',5-trichlorobiphenyl as substrates and $50 \mathrm{ml}$ phenol as co-substrate, in the biphasic cultures. The flasks were inoculated with $5 \times 10^{5}$ cells of each species, incubated at $27^{\circ} \mathrm{C}, 120 \mathrm{rpm}$ and the growth were evaluated by optical density $\left(\mathrm{OD}_{600}\right.$, Shimadzu UV Photometer).

Growth occurred in both phases, so, the kinetics in the multiphase liquor were described by the Monod-Haldane equation, where: $\mu_{\max }$ was the maximum specific growth rate; $\mathrm{S}$ was the substrate level; $\mathrm{K}_{\mathrm{s}}$ was the saturation constant and $\mathrm{K}_{\mathrm{i}}$ was the inhibition constant. The specific growth rates were obtained by using the $\mathrm{OD}_{600}$-data and the kinetic parameters were estimated by linear and nonlinear regression analyses:

$$
\mu=\frac{\mu_{\max } S}{K_{s}+S+S^{2} / K_{i}}
$$

\section{Analytical methods}

The ration of adhered cells to phenol to cells in the aqueous phase was obtained by centrifuged cultures at $12000 \mathrm{~g}$ for $10 \mathrm{~min}$ at $4^{\circ} \mathrm{C}$, the resulting pellets were washed twice in distilled water. The supernatants with phenol and cells were mixed with ethanol-acetone-chloroform (10:10:2, $\mathrm{vol} / \mathrm{vol} / \mathrm{vol})$, mixed for $15 \mathrm{~min}$ and centrifuged again; then the obtained pellets were washed twice. The $\mathrm{OD}_{600}$-pellet suspensions were determined by the spectrophotometer.

Ten-ml cultures were homogenized with $\mathrm{Na}_{2} \mathrm{SO}_{4}$ and

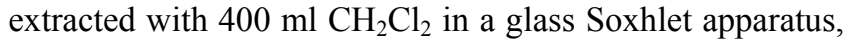
to analyze the chlorinated compounds. The $\mathrm{CH}_{2} \mathrm{Cl}_{2}$ extract was reduced and exchanged to hexane using a concentrator, and treated with acid-activated copper powder to remove elemental sulfur. PCBs were eluted with $100 \mathrm{ml}$ hexane, 

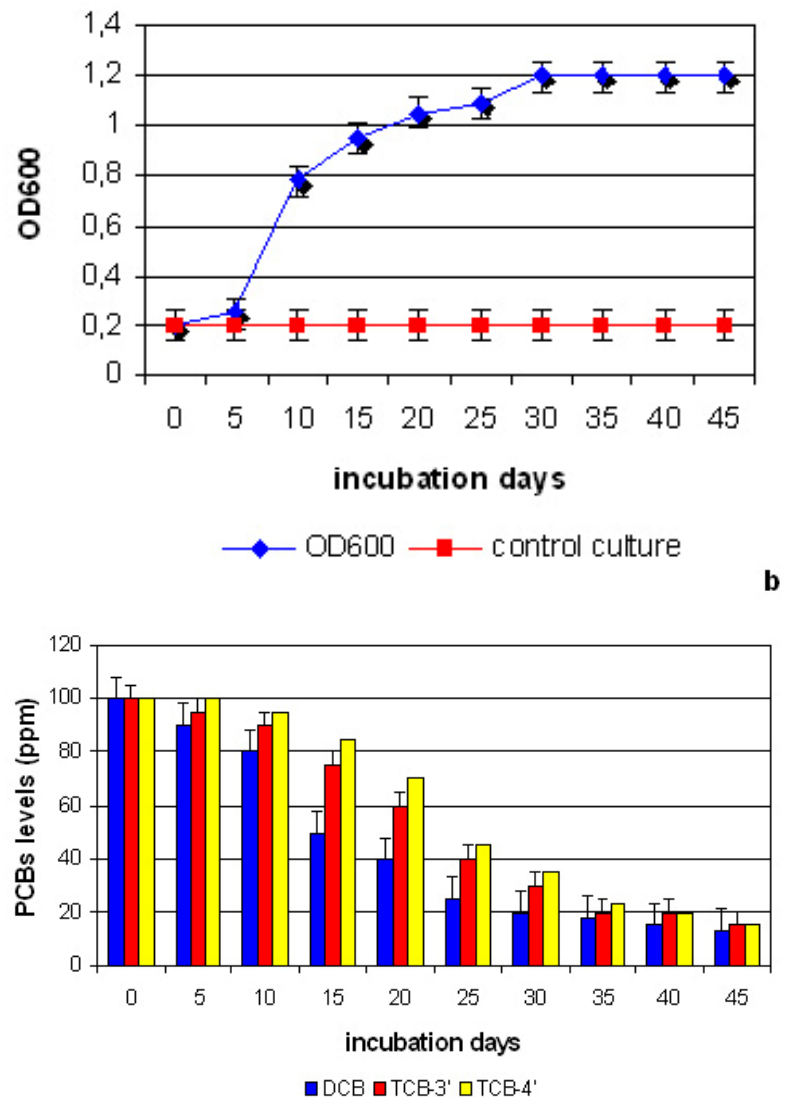

Figure 2. Growth curves (a) and PCBs concentrations (b) of acclimated consortium.

then these extracts were reduced to $1 \mathrm{ml}$ in a TurboVap (Zymark Corp.) (Kannan et al. 1997).

Extracts were analyzed on Varian 3400CX -GC with electron capture detector (GC/ECD) for primary quantitation, and ion trap mass spectrometric (GC/ITMS) detector to congeners confirmations. The columns ( $30 \mathrm{~m} \mathrm{x}$ $0.25 \mathrm{~mm}$ ) were coated with $0.25 \mu \mathrm{m}$ DB-5 and DB-XLB for the ECD and ITMS, respectively. The GC/ECD oven was programmed from $120^{\circ} \mathrm{C}$ to $260^{\circ} \mathrm{C}$ at $2^{\circ} \mathrm{C} \cdot \mathrm{min}^{-1}$, and the $\mathrm{GC} / \mathrm{ITMS}$ oven was programmed from $60^{\circ} \mathrm{C}$ to $280^{\circ} \mathrm{C}$ at $4^{\circ} \mathrm{C} \times \min ^{-1}$. Both instruments were calibrated by serial dilutions of PCB-standard mixtures and non-chlorobiphenyl congeners. Blanks did not contain any target PCB above the nominal specific detection limit (ca. 1 ng. $\mathrm{g}^{-1}$ dry weight) and the mean PCB recovery was ca. $86 \%$.

Growth in chlorinated substrates presence was measured by chloride release with an specific and reference electrode (Microprossesin pMX 2000/ION; WissenchaftlichTechnische Werkstatten GmbH, Weilheim, Germany), using $\mathrm{HCl}$-solution as standard.

\section{Statistical analysis}

Means, standard deviations, regressions and variance analysis (ANOVA) were performed using SPSS/PC + Version 5.0 (Wayne, 1996), and the significance levels were set at $\mathrm{P}=0.01$. Triplicate assays were performed for each set of test conditions.

\section{RESULTS AND DISCUSSION}

Debaryomyces castelli Capriotti (1958), Debaryomyces maramus di Menna (1954) and Dipodascus aggregatus Francke-Grosmann (1952) represented $72 \%$ of the isolated yeasts. The mixed culture was composed by equal numbers of these dominant and more efficient species. Indeed, their abilities to grow on each PCBs as carbon sources were evaluated by the $\mu$-values (Table 1 ).

The DCB, TCB-3' and TCB-4'degradation were observed after 5 and 20 days incubation period for the acclimated and non-acclimated consortium, respectively (Figure 1a and Figure 2a). However, the $\mathrm{OD}_{600}$ reached by both communities at $35^{\text {th }}$ days were not significant different $(\mathrm{P}>$ 0.05 ), and the pollutants were transformed to significant low levels in both cultures; although halves concentrations were reached at $40^{\text {th }}$ days in the pre and non-acclimated flasks, respectively (Figure 1b and Figure 2b). 


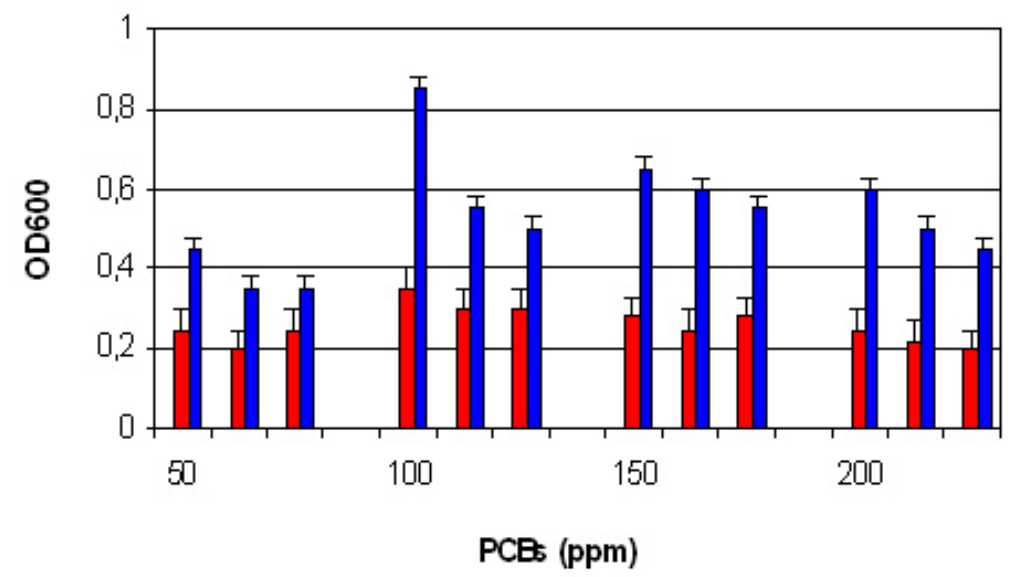

a monophasic a biphic

Figure 3. Specific growth rates $\left(\mu, h^{-1}\right)$ of the consortium in both systems enriched with PCBs.

The $\mu$-data, specific growth rates, increased from 0.11 to $0.65 \mathrm{~h}^{-1}$ in the biphasic medium and from 0.07 to $0.28 \mathrm{~h}-1$ in the monophasic assays, when the yeasts were precultured with PCBs. While $\mu$ increased with the xenobiotic levels in the biphasic medium, this parameter showed no significant variability in the monophasic ones (Figure 3). So, the performance of the biphasic was better than the monophasic system, although in both cases the substrate levels had different effects on the yeast activities. It must be pointed out that the surface-fixed cells were important in the degradation of hydrophobic pollutants, so the phenol presence increased the PCBs bioavailability and their uptake.
The $\mu$-values were twice as high in the water-organic assays, with $\mu=0.65 \mathrm{~h}^{-1}$ in this culture and $0.28 \mathrm{~h}^{-1}$ in the aqueous system. Likewise, the inhibition was lower in the biphasic $\left(\mathrm{K}_{\mathrm{i}}=16 \mathrm{mg} \mathrm{l}^{-1}\right)$ than in the aqueous culture $\left(\mathrm{K}_{\mathrm{i}}=\right.$ $\left.8.5 \mathrm{mg} \mathrm{l}^{-1}\right)$, this could be due to the high solubility of the metabolites in phenol presence. Similar saturation constants $\left(\mathrm{K}_{\mathrm{s}}=0.62 \mathrm{mg} \mathrm{l}^{-1}, \mathrm{~K}_{\mathrm{s}}=0.73 \mathrm{mg} \mathrm{l}^{-1} ; \mathrm{P}>0.05\right)$ were observed in both experiments.

During the incubation period, the yeasts distribution in the aqueous and phenolic phases were significantly different $(\mathrm{P}$ $<0.05)$, the cells partitioning showed that cells adhered to the organic drops when the shaker stopped. These data and the microscopic observations revealed that yeasts grew in

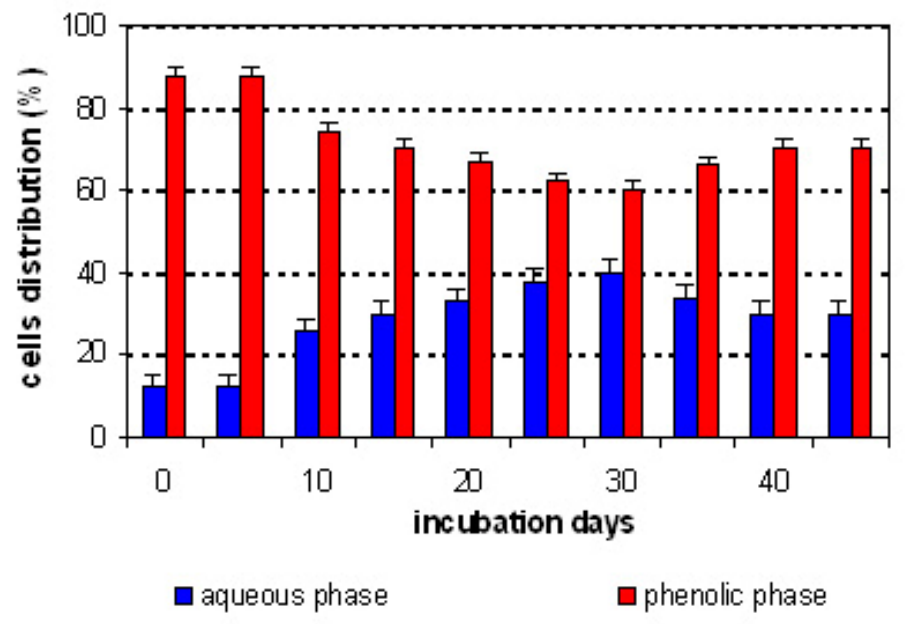

Figure 4. Yeast cells partitioning in the phenolic and aqueous phases. 
both phases just like in the liquid-liquid interface (Figure 4).

Significantly better adaptation was observed in the consortium in relation to each species alone in the biphasic assays; moreover, phenol presence incremented the interfacial associated cells and the biodegradation of hydrophobic organic pollutants as was shown by other authors (Köhler et al. 1994; Owen et al. 1997).

In two-phase systems, the compounds diffuse from the organic to the aqueous compartment, yeasts bioconverted the pollutants in the interfacial and water-phase and the metabolites accumulated in the organic ones. So, the relevance of this culture type was based on the avoiding of the substrate inhibition and increasing tolerance to great xenobiotic concentrations in contact with the fungi, finally, the high bioavailability improved the detoxification rates.

Biphasic system with water-heptamethylnonane to evaluate naphthalene degradation by Artrobacter spp. (Focht, 1997), and water-silicone oil for di- and trichlorobenzene by bacteria and yeasts spp. (Ascon-Cabrera and Lebeault, 1993; Kim and Picardal, 2001) had been performed. Wild yeasts with $n$-hexadecane and dichloro- and trichlorobenzene as pollutants were assessed (Romero et al. 2002), but in these reports with biphasic assays, other pollutants and species were tested.

Scarce studies were realized on yeast biodegradation potential of biarilic compounds, only Trichosporon spp., Debaryomyces vanrijiae, Candida spp. and Rhodotorula spp. had been referred as efficient species (Hammer et al. 1998; Lange et al. 1998; Romero et al. 2001). Indeed, total yeast number and the ratio between red to other yeasts were suggested as pollution indexes (Spencer and Spencer, 1997). In this study, two different Debaryomyces species and Dipodascus aggregatus were confirmed as effective PCBs-degraders, being the first reference on their conspicuous degradation potential.

The feasibility of bioremediation is based on the presence of efficient microbial populations and pollutant bioavailability (Madsen, 1997; Head, 1998). The tested yeasts and the organic-water system assayed in this research put forward the possibility that hydrophobic substrates could be mineralized in natural habitats by wild yeast consortium (Dighton et al. 2005). This event aimed towards the applications of the results by environmental biotechnologies to detoxify polluted areas (Dighton, 2003; Arora, 2004).

In conclusion, we confirmed that the yeast consortium biotransformed the substrates and revealed that a significant cell percentage fixed to the organic drops, pointing out the relevance of the interfacial area in the biodegradation processes. The presence of a water-organic system increased the adaptation of degrading yeasts and pollutants biotransformation; so, this system could improve microbial selection and the bioremediation of poorly water-soluble pollutants.

\section{REFERENCES}

ARORA, D.K. Fungal biotechnology in agricultural, food, and environmental applications. CRC Press, Mycology series, vol. 23. 1st. ed. USA, 2004. 700 p. ISBN 0-82474770-4.

ABRAMOWICZ, D.A. Aerobic and anaerobic biodegradation of PCBs: a review. Biotechnology, 1990, vol. 10 , no. 1, p. 241-251.

ASCON-CABRERA, M. and LEBEAULT, J.M. Selection of xenobiotic-degrading microorganisms in a biphasic aqueous organic system. Applied and Environmental Microbiology, 1993, vol. 59, no. 6, p. 1717-1724.

DIGHTON, J. Fungi in ecosystem processes. CRC Press, Mycology series, vol. 17. USA, 2003. 424 p. ISBN 0-82474244-3.

DIGHTON, J.; WHITE, J.F. and OUDEMANS, P. The fungal community. CRC Press, Mycology series, vol. 23. USA, 2005. 752 p. ISBN 0-8247-2355-4.

FOCHT, D.D. Aerobic biotransformation of polychlorinated biphenyls. In: HURST, C.J. ed. Manual of environmental microbiology. Washington, D.C., American Society for Microbiology Press (ASMP), 1997, p. 811-817.

HAMMER, E.; KROWAS, D.; SCÄFER, A.; SPECHT, M.; FRANCKE, W. and SCHAUER, F. Isolation and characterization of a dibenzofuran degrading yeast: identification of oxidation and ring cleavage products. Applied and Environmental Microbiology, 1998, vol. 64, no. 6, p. 2215-2219.

HAVEL, J. and REINEKE, W. The influence of physicochemical effects on the microbial degradation of chlorinated biphenyls. Applied Microbiology and Biotechnology, 1995, vol. 43, no. 7, p. 914-919.

HEAD, I.M. Bioremediation: towards a credible technology. Microbiology, 1998, vol. 144, no. 3, p. 599608.

KANNAN, K.; MARUYA, K.A. and TANABE, S. Distribution and characterization of polychlorinated biphenyl congeners in soil and sediments from a superfund site contaminated with Aroclor 1268. Environmental Science and Technology, 1997, vol. 31, no. 8, p. 14831488.

KIM, S. and PICARDAL, F. Microbial growth on dichlorobiphenyls chlorinated on both rings as a sole carbon and energy source. Applied and Environmental Microbiology, 2001, vol. 67, no. 9, p. 1953-1955. 
KÖHLER, A.; SCHÜTTOFF, M.; BRYNIOK, D. and KNACKMUB, H.J. Enhanced biodegradation of phenanthrene in a biphasic culture system. Biodegradation, 1994, vol. 5, no. 1, p. 93-103.

KURTZMAN, C.P. and FELL, J.W. The yeasts, a taxonomic study. Elsevier Science, $4^{\text {th }}$ ed. The Netherlands, 1998. 1934 p. ISBN 0-444-81312-8.

LANGE, J.; HAMMER, E.; SPECHT, M.; FRANCKE, W. and SCHAUER, F. Biodegradation of biphenyl by the ascomycetous yeast Debaryomyces vanrijiae. Applied and Environmental Microbiology, 1998, vol. 50, no. 3, p. 364368.

LÖSER, C.; SIEDEL, H.; HOFFMANN, P. and ZEHNSDORF, A. Bioavailability of hydrocarbons during microbial remediation of a sandy soil. Applied Microbiology and Biotechnology, 1999, vol. 51, no. 1, p. 105-111.

MADSEN, E.L. Methods for determining biodegradability. In: HURST, C.J. ed. Manual of environmental microbiology. Washington, D.C., American Society for Microbiology Press (ASMP), 1997, p. 709-720.

OUDIN, P.; TOTH, J.A.; BONALDY, R. and BALOGH, C. Quantization of intracellular polychlorobiphenyls during growth of Rhodotorula glutinis. Biotechnology Techniques, 1999, vol. 13, no. 1, p. 101-105.

OWEN, S.A.; RUSSELL, N.J.; HOUSE, W.A. and WHITE, G.F. Re-evaluation of the hypothesis that biodegradable surfactants stimulate surface attachment of competent bacteria. Microbiology, 1997, vol. 143, no. 11, p. 3649-3659.

ROMERO, M.C.; HAMMER, E.; HANSCHKE, R.; ARAMBARRI, A.M. and SCHAUER, F. Biotransformation of biphenyl by filamentous fungus Talaromyces helicus. World Journal of Microbiology and Biotechnology, 2005, vol. 21, no. 1, p. 101-106.

ROMERO, M.C.; REINOSO, E.H.; MORENO KIERNAN, A. and CÓRDOBA, S. Biodegradation of glyphosate by wild yeasts. Revista Mexicana de Micología, 2004, vol. 19, p. 45-50.

ROMERO, M.C.; SALVIOLI, M.L.; CAZAU, M.C. and ARAMBARRI, A.M. Pyrene degradation by filamentous soil fungi and yeast species. Environmental Pollution, 2002, vol. 117, no. 1, p. 159-163.

ROMERO, M.C.; HAMMER, E.; CAZAU, M.C. and ARAMBARRI, A.M. Selection of autochthonous yeast strains able to degrade biphenyl. World Journal of Microbiology and Biotechnology, 2001, vol. 17, no. 6, p. 591-594.
SIETMANN, R.; HAMMER, E.; SPECHT, M.; CERNIGLIA, C.E. and SCHAUER, F. Novel ring cleavage products in the biotransformation of biphenyl by the yeast Trichosporon mucoides. Applied and Environmental Microbiology, 2001, vol. 67, no. 7, p. 4158-4165.

SIETMANN, R.; HAMMER, E. and SCHAUER, F. Biotransformation of biarylic compounds by yeasts of the genus Trichosporon. Systematic and Applied Microbiology, 2002, vol. 25 , no. 3 , p. 332-339.

SPENCER, J.F.T. and SPENCER, D.M. Ecology: where yeast live. In: SPENCER, J.F.T. and SPENCER, D.M eds. Yeasts in natural and artificial habitats. Berlin, SpringerVerlag Berlin, 1997, p. 33-58.

STRINGER, R. and JOHNSTON, P. Chlorine and the environment. Kluwer Academic Publishers, $1^{\text {st }}$ ed. UK, 2001. 644 p. ISBN 0-7923-6797-9.

SWANNELL, R.P.J.; LEE, K. and MC DONAGH, M. Field evaluation of marine oil spill bioremediation. Microbiological Reviews, 1996, vol. 60, no. 3, p. 342-365.

U.S. Environmental Protection Agency (USEPA), (EPA 2003-40CFR761). In: Protection of environment. Chapter 1, part 761, vol. 28, Polychlorinated biphenyls (PCBs) manufacturing, processing, distribution in commerce and use prohibitions. 2003, p. 579-708.

WAYNE, W.D. Bioestadística. México, Uteha, $2^{\text {nd }}$ ed., 1996, 250 p. ISBN 0-3903-6797-9. 